\title{
Sobre la portada
}

L a fotografía que ilustra la portada de este número fue tomada después de 1976 y antes de 1982, no se conoce al autor y forma parte de un expediente sobre las obras de remodelación que se efectuaban con el fin de recuperar el inmueble del siglo XVIII y que fuera la casa de don Valentín Gómez Farías, destacado liberal y político del siglo XIX. ${ }^{1}$

Los detalles de la fachada, que con las obras se modificaron, dan cuenta de una casona, en el antiguo pueblo de Mixcoac, con la típica arquitectura mexicana del siglo xVIII. La imagen en blanco y negro que nos ocupa fue tomada desde un costado del frente, de norte a sur, alrededor del mediodía, dada la proyección de las sombras. Se puede apreciar, en el margen inferior izquierdo, que en aquellas fechas aún pasaba una calle por el frente de la casa; se alcanza a ver la guarnición de la banqueta empedrada y que hasta la actualidad permanece, sólo que ya no sobresale. Los vidrios de las ventanas del cuerpo superior reflejan la copa del árbol que se encuentra enfrente. Se observan un frontón, recortado por una cornisa con dos pináculos a los extremos, un pretil y, en la parte superior, una hermosa hornacina que resguarda desde hace muchos años una virgen de Guadalupe y que no se puede apreciar dado del ángulo de la foto. Los arcos de medio punto tienen una barandilla que llega casi hasta la mitad. El primer cuerpo presenta cuatro balcones con herrería de la época, se alcanzan a ver tres desagües y apenas se perciben dos faroles a los lados del portón; en la parte superior una cornisa divide ambos cuerpos. En el lado superior izquierdo de la imagen aparecen las ramas de uno de los frondosos árboles de la plaza, un poste de luz con sus cables $y$, al fondo, parte de la fachada de lo que fuera la casa de Ireneo Paz y después el convento de dominicas. Aunque no se alcanza a apreciar del todo, el frente ostentaba, del lado izquierdo de la entrada, el rótulo de Bibliotecas Mexicanas, A. C.

Justo en la puerta se puede ver a un hombre, de pantalón oscuro y camisa clara, entrando en la casa. También se distingue un pequeño árbol de lo que era una hilera que estaba alineada a lo largo de la banqueta y que con el tiempo y la remodelación de la plaza desapareció.

'Véanse "Fotos de remodelación, 1982, Instituto Mora", Biblioteca Ignacio de la Torre Villar, Instituto Mora, CD, y "Dictámenes, Instituto Mora", Biblioteca Ignacio de la Torre Villar, Instituto Mora, fotocopias. 


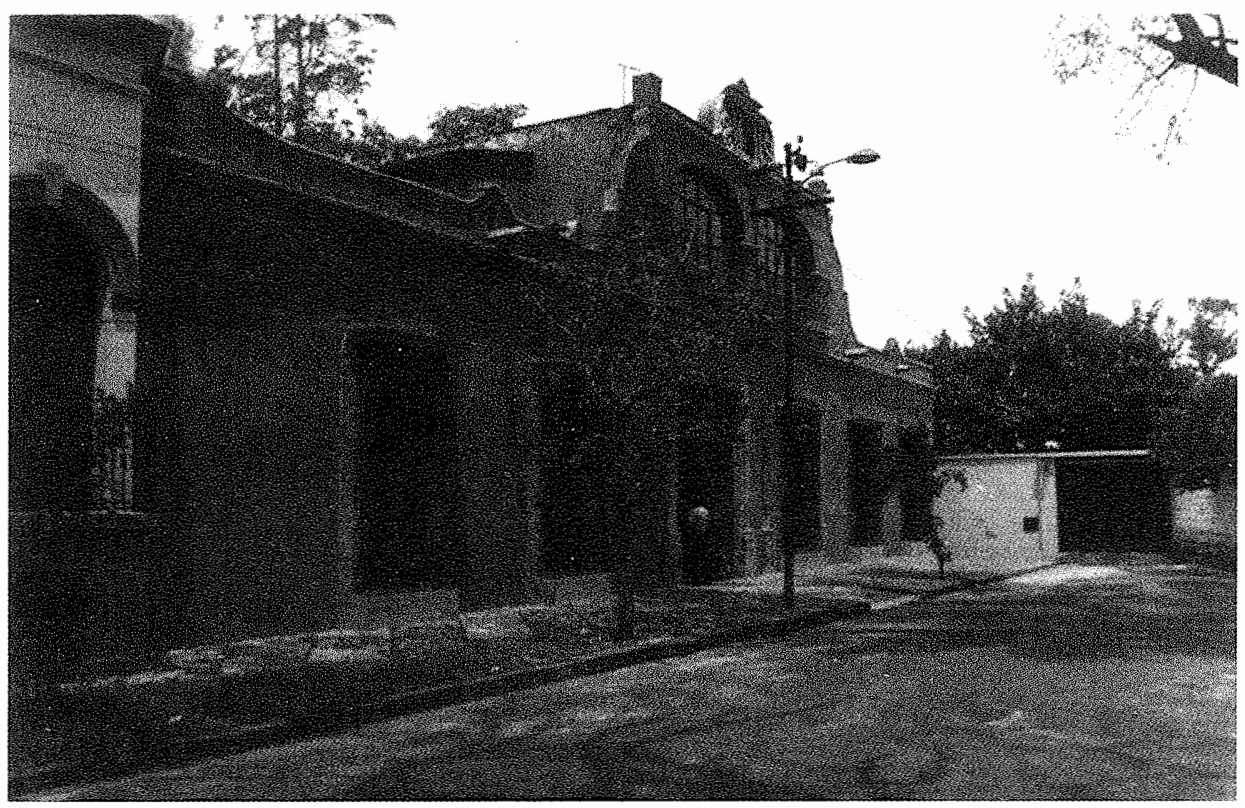

Un conjunto de tres fotografías más completa la imagen de cómo lucía la casa y parte de la plaza cuando era la sede de Bibliotecas Mexicanas. Para 1982, año en que la Dirección de Monumentos Históricos realizó una inspección del inmueble, la plaza se había transformado y la casa estaba en proceso de una profunda restauración y adaptación para albergar al Instituto Mora.

La casa tiene una larga historia. Aunque su edificación se remonta al siglo XVIII, se sabe que en los años treinta del siglo XIX se pensó establecer una escuela de primeras letras en ella. En 1840 doña Isabel López Padilla, esposa de don Valentín Gómez Farías, la compró a los curas de la iglesia de San Juan, y durante muchos años fue propiedad de la familia y sus herederos. ${ }^{2}$ La casa, por sus características arquitectónicas y por haber sido residencia de don Valentín Gómez Farías, fue declarada monumento histórico en el siglo XX, aunque seguía siendo una casa particular en donde vivían los descendientes de don Valentín. Las dimensiones de la propiedad eran considerables, pues ocupaba más de siete mil metros cuadrados; con el tiempo se fraccionó y se vendieron algunos predios, quedando la casa y su huerta en una superficie de 2240 metros cuadrados, mismos que se conservan hasta la fecha.

\footnotetext{
${ }^{2}$ Véase Regina Hernández Franyuti, Laura Suárez de la Torre, Laura Solares Robles y Graciela de Garay, Culebra de nubes, Instituto Mora, México, 1991.
} 
En 1976 el destino de la casa se volvió público, pues fue vendida a Bibliotecas Mexicanas, A. C., convirtiéndose en su sede. El gobierno federal, algunos organismos públicos descentralizados, empresas paraestatales y empresas privadas integraron una asociación no lucrativa cuyo fin era:

adquirir, mantener, preservar y administrar bibliotecas, archivos, documentos, material fímico, fotográfico y audiovisual y acervos bibliográficos y documentales relacionados con el patrimonio histórico de México; promover y realizar la investigación y el análisis de aspectos relativos a la historia de México; editar, publicar y distribuir libros y revistas y material filmico y audiovisual, y capacitar recursos humanos en el área de archivonomía, bibliotecología y restauración y conservación de libros y documentos. ${ }^{3}$

El fondo con que se inició este proyecto fue la rica biblioteca de José Ignacio Conde, quien comenzó a formarla en 1941 con aproximadamente 300 ejemplares. Con el tiempo Ignacio Conde fue agrandando el acervo con la adquisición de diversas bibliotecas de literatos, escritores y personajes notables como Vicente Riva Palacio y José María Roa Bárcena, entre otros. Compra de libros nuevos o de lance, catalogados como "raros", manuscritos inéditos, libros decimonónicos y otras joyas de papel y tinta conformaron una de las colecciones más interesantes y valiosas, que llegó a reunir unos 14000 ejemplares principalmente de temas históricos. José Ignacio Conde fue el director ejecutivo de la biblioteca, que se inauguró el 29 de noviembre de 1976.

Después, Bibliotecas Mexicanas donó el inmueble al Instituto de Investigaciones Dr. José María Luis Mora, aunque la donación del inmueble se protocolizó hasta 1986. Entre los acuerdos de la donación también se incluía el acervo bibliográfico "Biblioteca Conde", ya que se consideró que el Instituto contaba con la estructura necesaria para cumplir cabalmente con los objetivos planteados en la fundación de Bibliotecas Mexicanas.

En la antigua casa de la Plaza de San Juan en el barrio de Maninaltongo, en la que alguna vez se pensó en establecer una escuela de primeras letras, con el paso del tiempo "el destino, o acaso una simple coincidencia, hizo que el inmueble fuese, finalmente, sede de un centro de cultura". 4

El Instituto de Investigaciones Dr. José María Luis Mora fue creado por decreto presidencial el 24 de septiembre de 1981 como un organismo público descentralizado con la finalidad de desarrollar investigación e impartir docencia en el campo de las ciencias sociales. El edificio principal se conserva en magníficas condiciones, y el acervo de la biblioteca crece día con día.

Claudia Patricia Pardo Hernández

${ }_{3}^{3}$ Bibliotecas Mexicanas, A. C., folleto impreso en la ciudad de México el 29 de noviembre de 1976.

${ }^{4}$ Laura Solares Robles, "Historia de una casa" en Hernández et al., Culebra de nubes, op. cit., p. 53. 


\section{SECUENCIE}
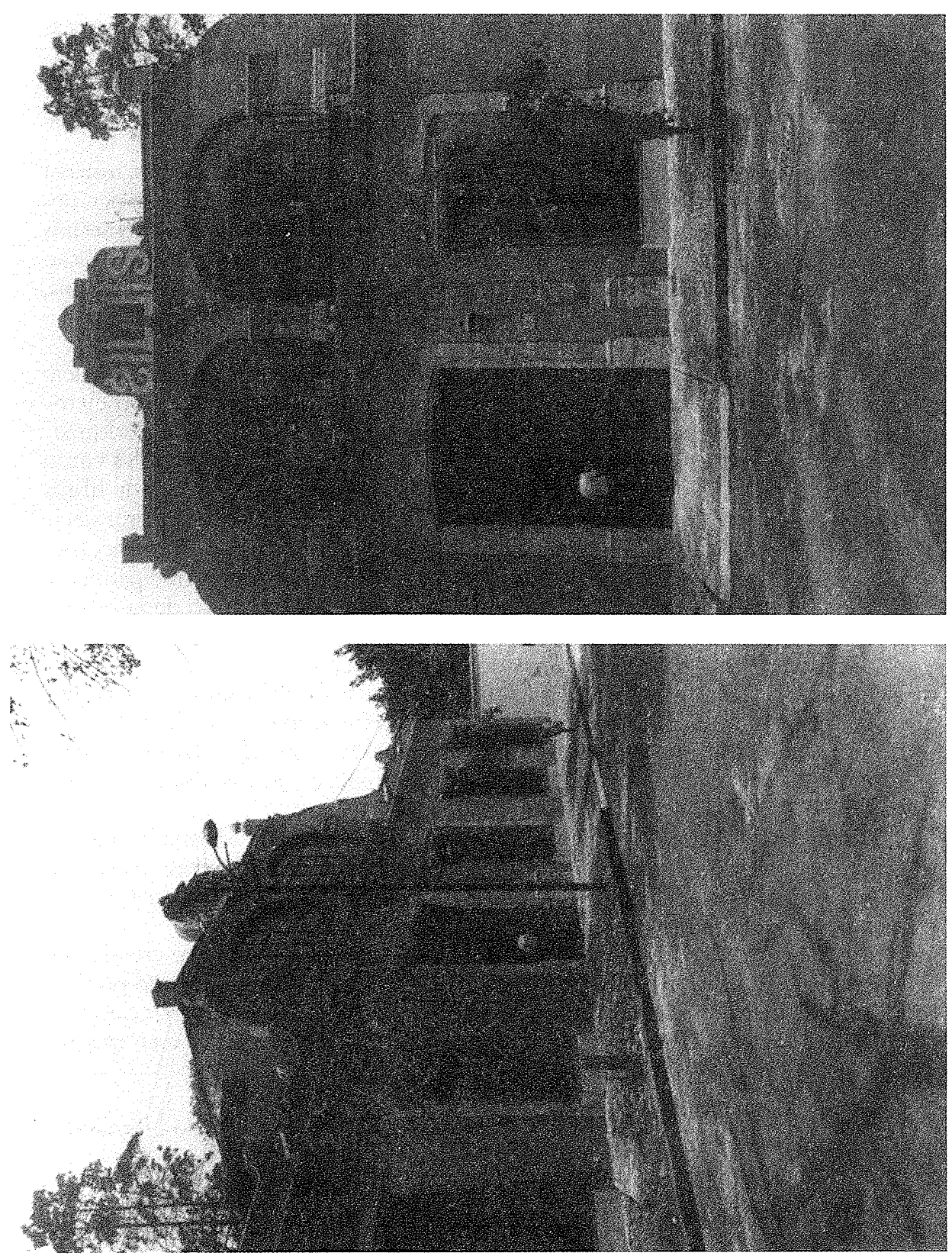